\title{
Palavras carnais: sobre re-lembrar e re-esquecer, ser e não ser, entre os Filhos do Erepecuru
}

\author{
Julia F. Sauma \\ - Universidade de São Paulo / São Paulo, SP, Brasil \\ $\boldsymbol{\nabla}$ juliasauma@gmail.com
}

RESUMO

Neste trabalho, exploro o potencial analítico daquilo que Martin Holbraad denomina 'método ontográfico', a partir das reflexões dos Filhos do Erepecuru - castanheiros, ribeirinhos e remanescentes de quilombos - acerca do processo de lembrar e esquecer relatos sobre os seus antepassados, e a atuação dessas palavras sobre o corpo. Inicio com uma consideração sobre a importância que os Filhos conferem ao esquecimento dos seus relatos sobre a vinda dos antigos para o rio Erepecuru, município de Oriximiná, Pará. A partir dessa questão etnográfica, descrevo como a necessidade de esquecer e os cuidados inerentes ao ato de lembrar estão relacionados ao poder das palavras de mobilizar forças e sentimentos, curas e doenças, para dentro da pessoa. Tal reflexão etnográfica possibilita sugerir como a linguagem e a experiência são relacionadas pelos Filhos do Erepecuru, e como essa relação opera com base em uma ontologia móvel.
PALAVRAS-CHAVE

Remanescentes de quilombos, Ontologia, Esquecimento, Palavras, Corpo. 


\section{UM COMEÇO POSSÍVEL'}

Palavras que pegam na carne, que costuram, consertam, enrolam, abrem e fecham, adoecem e curam. Falas, rezas, histórias que protegem, que entristecem, que machucam. Não há sentido figurativo nessas colocações, não há necessidade de criar modos de "justapor palavras e experiência num estreito colamento fenomenológico" (Campos, Campos e Pignatari, 1956), pois as palavras já são coisas $^{2}$ que adentram a carne, o corpo, a pessoa, transformando-na. Quer dizer, no mundo possível que apresento aqui, mundo este aberto por negros escravos fugidos e mantido por seus descendentes - os Filhos do Erepecuru (doravante Filhos) - a relação entre palavra e experiência é interna: a palavra e a experiência definem-se mutuamente. Tudo que pode ser feito em contra e a favor dessas palavras, e das forças e dos sentimentos que elas carregam, é ter cuidado com a forma com que nos aproximamos delas.

Esse é o fim que trago para o começo, visando orientar um pouco o que segue, e ao qual retornarei em breve. Antes disso, porém, volto a minha atenção brevemente ao uso da noção de um 'mundo possível' como quilha desse exercício de refletir sobre como os Filhos do Erepecuru-que são remanescentes e quilombolas do oeste paraense, castanheiros e ribeirinhos, e meus amigos e interlocutores - pensam a palavra. Quilha, posto que o 'possível' é o elemento fundamental que tiro do 'método ontográfico' (Holbraad, 2012) na antropologia, operando como estrutura forte e discreta das minhas reflexões; possibilitando a abertura de novos caminhos para a antropologia no trabalho com povos remanescentes de quilombos; e aproximando este ensaio de uma discussão teórica acirrada na disciplina, sem deixá-la sufocar a etnografia.

Nesse sentido, entendo o conceito de ontologia na antropologia como operando junto com o conceito de política, conforme proposto por Viveiros de Castro, Pedersen e Holbraad (2014: n.p., minha tradução, ênfase original), em que eles definem:

o conceito antropológico de ontologia como uma multiplicidade de formas de existência que são efetuadas por meio de práticas concretas, em que a política se transforma em elicitação não cética dos múltiplos potenciais de como as coisas poderiam ser-aquilo que Elizabeth Povinelli, no nosso entendimento, denomi$n a$ 'the otherwise' [o afora].

Note-se aqui que os autores chegam a essa definição por contraste, após definir os conceitos filosófico e sociológico de ontologia: o primeiro entendido, pelos autores, como forma de descobrir e disseminar a verdade sobre 'como as coisas são'; e o segundo, como crítica desqualificadora de todo projeto ontológico
1 O presente trabalho é uma versão ampliada de trabalhos apresentados, primeiro, no Laboratório de Antropologia e História do Programa de Pós-graduação em Antropologia Social do Museu Nacional (UFR]), em novembro de 2014, e, segundo, no Centro de Estudos Ameríndios da USP, em julho de 2016. Agradeço a todos os que participaram desses encontros pelos comentários, que me ajudaram a refinar as ideias aqui contidas, especialmente a Olívia Gomes da Cunha, Marcelo Mello Rogério Brittes, Ana Carneiro, Renato Sztutman, Marta Amoroso, Valeria Macedo, Luísa Girardi, Joana Cabral de Oliveira e Leo Braga; enfatizando, é claro, que os erros e exageros são somente meus. Este trabalho foi escrito durante um período de pós-doutorado no Programa de Pós-graduação em Antropologia Social da USP, financiado pela Capes.

2 Os conceitos e expressões que aparecem em itálico no corpo do presente trabalho pertencem aos Filhos do Erepecuru, aspas simples e duplas são utilizadas, respectivamente, para conceitos analíticos próprios ou de outros autores e citações. 
por meio de sua própria versão de 'como as coisas deveriam ser'. A tríplice como as coisas são, como as coisas deveriam ser e como as coisas poderiam ser emerge, portanto, como três formas distintas de ação política que estão relacionadas, respectivamente, a três formas de conceber a ontologia: como verdade única, como múltiplas construções e como o possível.

Opto aqui pela terceira dessas formas, porque busco alcançar os projetos filosófico e sociológico, e portanto político, dos meus interlocutores, conforme colocado em outro lugar (Sauma, 2013). Opção que tomo, em larga medida, em contraposição ao projeto sociológico (e portanto filosófico e político) ocidental que ainda domina os estudos antropológicos sobre os povos remanescentes de quilombos no Brasil e além³. Nesse sentido, também aceito que o método ontográfico-que funciona a partir do mapeamento das premissas ontológicas dos discursos nativos (Holbraad, 2012)-, defendido por esses autores, é político em si, no sentido de envolver:

experimentações que são precipitadas pela exposição etnográfica a pessoas cujas vidas são, de um jeito ou de outro, contra as atuais ordens hegemônicas (Estado, Império e Mercado, em suas convergências sempre voláteis e violentas), assim, a política da ontologia ressoa, em sua essência, as políticas dos povos que a suscitam (Holbraad, Pedersen e Viveiros de Castro, 2013: 5, minha tradução).

Apresento aqui, portanto, uma experimentação precipitada pela forma em que os Filhos do Erepecuru pensam e explicam as palavras; elementos que nós achamos que dominamos. Essa experimentação vai, assim, ao cerne do objetivo político do método ontográfico: colocar formas estabelecidas de pensamento sob pressão incessantemente, inclusive aquelas que pertencem à academia. Veremos, nesse exercício, como a memória-elemento que domina a forma em que muitos antropólogos definem o uso da palavra por seus interlocutores-é uma prática cheia de perigos para os Filhos do Erepecuru. Assim, veremos também a singularidade da palavra que dá forma aos seus relatos e narrativas, trazendo consigo outra forma de existência, outra forma de conceber e agir não somente em relação à palavra, à fala, ao ato de lembrar e esquecer, mas também em relação ao corpo, à pessoa, ao movimento e, fundamentalmente, a qualquer coisa.
3 Projeto que, portanto, limita a nossa capacidade de nos relacionarmos com esses povos em um plano político estatal, que falhou com eles abundantemente e continuamente (ver Sauma 2013, 2014 e 2015), para não dizer atualmente: como parte das manobras ilegítimas do atual governo interino, a responsabilidade de titulação de terras quilombolas foi retirada do Incra (Instituto Nacional de Colonização e Reforma Agrária) e transferida para o Ministério de Educação e Cultura, que é liderado pelo deputado federal Mendonça Filho (DEM-PE), autor da Ação Direta de Inconstitucionalidade $\mathrm{n}^{\circ}$ 3239 sobre o decreto $n^{\circ} 4887 / 2003$, que regula os procedimentos de titulação. Ver nota da Coordenação Nacional de Articulação das Comunidades Negras Rurais Quilombolas em: https://www. socioambiental.org/sites/blog. socioambiental.org/files/nsa/arquivos/nota_da_conaq.pdf.

\section{RE-LEMBRAR}

Os Filhos do Erepecuru contribuíram de forma decisiva para a primeira titulação de terra quilombola no Brasil, a qual depende de laudos etno-históricos escritos por antropólogos. Mesmo assim, e mesmo os conhecendo há uma década, falar com os Filhos sobre os seus antepassados e sobre o passado, de forma geral, 
sempre é uma tarefa difícil. Não foi diferente para os antropólogos que se encarregaram da tarefa de confeccionar o laudo antropológico das comunidades remanescentes de quilombo do município de Oriximiná na década de 1990. Eliane O'Dwyer (2002), a antropóloga que escreveu o laudo que levou à titulação do Erepecuru em 1997, conta que, no momento crucial de sua chegada naquela área para iniciar a coleta de dados de memória oral que compreenderia o relatório exigido pelo Incra, os Filhos chegaram a barrar a sua subida até as comunidades, em um primeiro momento, forçando-a a conduzir as suas reuniões na cidade. Refletindo sobre o que essa experiência etnográfica dizia sobre aquele povo, O'Dwyer oferece as seguintes observações:

Esses grupos, que se definem legalmente como "remanescentes de quilombos" e que vivem em territórios separados no al to curso do rio Trombetas e de seu afluente Erepecuru-Cuminá, costumam praticar, segundo nossa experiência etnográfica, formas de isolamento defensivo quando da entrada de estranhos nas localidades em que vivem, criando uma série de dificuldades de acesso às pessoas de fora, até quando as intenções destas são definidas em termos de conhecimento (O'Dwyer, 2002: 256, minha ênfase).

Segundo a autora, essas práticas de 'isolamento defensivo' também devem ser entendidas como práticas de 'isolamento consciente':

baseado na memória histórica e genealógica desses grupos sobre sua origem comum, recuperando-se, assim, a noção de Weber sobre a construção de "fronteiras rigorosas... que se fixam em pequenas diferenças de hábitos cultivados e aprofundados... em virtude de um isolamento monopolista consciente" (O'Dwyer, 2002: 257, minha ênfase).

Deparamo-nos, assim, com aquilo que David Scott (1991: 261) denomina uma 'narrativa de continuidades' - "continuidades entre o velho mundo e o novo mundo, entre o passado e o presente" - que tem embasado a antropologia dos povos de matriz africana nas Américas desde sua origem. A minha intenção é a de apontar os limites dessa narrativa-mesmo reconhecendo a sua importância política no passado - para a descrição etnográfica de como os Filhos do Erepecuru pensam as suas próprias práticas de moderação relacional, dentre as quais encontramos a estratégia de 'isolamento consciente', mesmo sem a construção de fronteiras rigorosas. Acredito que, ao trazer esse contraste, observaremos como as reflexões e práticas nativas evidenciam um mundo em que a agência da palavra e, portanto, do conhecimento e da memória não necessariamente produz a continuidade e a coletividade. Ou seja, veremos um mundo em que 
a busca pelo conhecimento não deve ser entendida, simplesmente, como uma busca neutra e/ou benevolente, pois tudo o que tem força também é perigoso e deve ser abordado cuidadosamente.

Os coordenadores da Associação de Remanescentes de Quilombos de Oriximiná, refletindo sobre o momento da demarcação durante o meu campo, mais de uma década depois, frequentemente lembravam de como foi difícil mobilizar os seus parentes e persuadi-los a falar com pesquisadores de fora, como O'Dwyer, mesmo para garantir os seus direitos. Segundo eles, essa desconfiança tinha e continua tendo uma razão muito clara, pois, como ouvi diversas vezes, "o remanescente não gosta de falar dessas coisas". Nas minhas conversas com os Filhos, o seu passado ancestral e, particularmente, qualquer menção à escravidão, aparece como algo que concedem re-lembrar ou, como eles falam, resgatar na luta por suas terras, em determinados momentos, mas que está sempre à beira de ser re-esquecido, em outros momentos. Como veremos na segunda seção, de diversas formas, esses dois mecanismos, que denomino como 're-lembrar' e 're-esquecer'4, são essenciais para a manutenção de um ficar tranquilos no Erepecuru, objetivo existencial dos Filhos que sempre requer muito trabalho, muito cuidado. Portanto, são esses atos que estruturam a etnografia que apresento aqui.

Partimos de um relato que Daniel Souza (Comunidade do Jauari) - envolvido há trinta anos em diversas campanhas estaduais e nacionais em defesa dos direitos quilombolas - contou para mim algumas vezes durante as nossas conversas sobre a luta pela titulação no Trombetas e no Erepecuru. Falando sobre a forma em que ele começou a ter ciência do passado do seu povo, Daniel contava que os velhos nunca gostavam de falar muito sobre o passado, utilizando expressões comuns entre os Filhos para marcar esse fato, como "esses velhos são perigosos" ou "esses velhos são enrolados demais". Portanto, a primeira vez em que ele escutou essa história foi do seu avô, de forma inesperada, durante uma caça, enquanto caminhavam na floresta a sós:

Eu tinha onze anos, eu lembro muito bem, porque matamos a queixada e o vovô partiu o bicho, me deu uma banda para levar nas costas e ele levou a banda maior. E começamos a voltar para casa, mas só andamos uma certa distância e o vovô viu que tinha deixado o terçado lá a trás, e voltamos no mesmo caminho para procurar, e o encontramos no lugar onde ele tinh a partido o bicho. O terçado estava assim de pé no tronco de uma árvore. Edaí o vovô de repente fez uma coisa, ele sentou e passou a mão nos ol hos, e vi que estava chorando, e ele me contou que ele tinha se lembrado das histórias dos antigos, sobre como tinham escapado dos engenhos, e como ficaram desesperados, perdidos na floresta, mas que tinham que escapar, e ele contou que os velhos eram escravos e de como os patrões botavam óleo nas mãos dos negros e queimavam para usar como candeia. Eo
4 A decisão de introduzir conceitos próprios aqui, no lugar de conceitos nativos, foi tomada como forma de solucionar dois problemas, um de ordem etnográfica e o outro de ordem lógica. Ambos serão abordados na segunda seção, mas adianto aqui que o prefixo 're-', designativo de repetição e reforço, busca enfatizar a questão que faz a conexão entre esses dois problemas: o fato de que, entre os Filhos, tratam-se de práticas interdependentes, ou seja, nesse contexto o mecanismo de lembrar sempre poderá ser seguido pelo mecanismo de esquecer, e vice-ver$s a$, infinitamente, em um futuro próximo ou distante-relação nada óbvia quando levamos em consideração que, segundo a semiótica ocidental, seria impossível conceber um mecanismo, técnica ou arte do esquecimento (Eco e Migiel, 1988).

5 Essa expressão é utilizada pelos Filhos para denotar um ideal que gira em torno da pessoa, feita na relação entre corpo e mente. É possível fazer conexões comparativas com a noção de 'tranquilidade' utilizada por Joana Overing (1989) para descrever a convivência entre os Piaroa. Infelizmente, não cabe aqui uma comparação minuciosa, algo que certamente farei no futuro, porém vale mencionar que, diferente da forma em que Overing usa essa expressão, a noção dos Filhos de ficar tranquilo não define um interior social. Nesse caso, a tranquilidade não diz respeito, necessariamente, à coletividade, uma vez que o Coletivo-aquele que almeja ficar tranquilo - não é nem o grupo, nem o indivíduo, mas um tipo de pessoa (ver Sauma, 2013). 
vovô falou que não era para eu contar essas histórias em casa, especialmente para as mulheres, porque era muito perigoso para elas escutar uma coisa dessas.

Ao longo dos anos, esse e outros relatos recorrentes do Daniel deixaram claro para mim que, apesar de ele argumentar, para os seus parentes, sobre a importância política de falar a respeito do seu passado ancestral de forma espontânea, fazê-lo não era muito fácil para ele, para não dizer dos parentes que não participam no movimento quilombola. Daniel e outras lideranças do Erepecuru e do Trombetas falam constantemente da "dureza" da "vida com o movimento", apesar da importância desse trabalho e da alegria que ele também traz, e, mesmo quando criticados por alguma atuação, o sacrifício desta vida é igualmente reconhecido pelos seus parentes. Para falar sobre esse passado, é preciso ter certo tipo de dom. Isso significa que em muitas reuniões

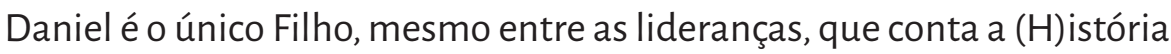
ancestral dos Filhos; ou seja, que fala da escravidão. Todos sabem que ele fará esse papel, que fá-lo-á bem, e, assim, seus parentes não precisam fazê-lo, não precisam falar dessas coisas perigosas, e podem até re-esquecer essas histórias de novo após tais eventos, por meio de técnicas específicas, como veremos na segunda metade deste trabalho. Contudo, isso não significa que os parentes do Daniel não falem de um passado ancestral.

Assim como O'Dwyer, quando cheguei no Erepecuru, em 2009, a minha presença suscitou certa desconfiança entre as famílias, a qual se dissipou com o tempo e por meio das minhas múltiplas visitas a cada casa, da minha participação nos seus trabalhos e festas. De qualquer jeito, seja no início cheio de desconfianças ou posteriormente, quando já era chamada para passar mais tempo com diferentes famílias, e apesar do fato de que eles não falam sobre a escravidão, os Filhos mais velhos (acima de 60 anos) nunca deixavam de se expressar, espontaneamente-e, com certeza, por conta da sua interação com outros pesquisadores-, sobre o que eles consideram ser ser remanescente ${ }^{6}$. Para falar sobre esse assunto, como O'Dwyer também escreve, um dos principais veículos utilizados é um mito que eles chamam de Lenda das Cobras Crandes (ver Lima, 1992; O'Dwyer, 2002; Sauma, 2013, 2014), que conta a chegada dos seus antepassados no Erepecuru. Resumidamente, o mito conta como a chegada de "negros escravos fugidos"` no Erepecuru desencadeou a briga entre duas cobras gigantes, irmã e irmão, donas dos dois principais rios da atual área quilombola, causando uma transformação cosmogônica que possibilitou o estabelecimento dos primeiros mocambos do rio Erepecuru.

Em outros trabalhos (Sauma, 2013, 2014), apresento a lenda para descrever uma paisagem ancestral, a presença latente dessa paisagem no Erepecuru contemporâneo, e a forma ideal de agir naquela paisagem, segundo os Filhos.
6 Vale notar que, entre eles, os Filhos utilizam essa designação, remanescente, com mais frequência que quilombola. Até certo ponto são designações sinônimas, mas os FiIhos também enfatizam o orgulho de ser remanescente e usam esse conceito não como forma de falar sobre "aqueles que restaram", mas sobre aqueles que tiveram a força de permanecer.

7 Designação comum entre os Filhos para falar dos seus antepassados e que marca a diferença entre eles (ver Sauma, 2013). 
Assim, identifico os princípios daquilo que chamo de 'ecologia cosmopolítica' dos Filhos do Erepecuru: um regime de conhecimentos e práticas, orientado à manutenção de um ficar tranquilo, que trata das relações e interações entre os diferentes elementos do cosmos, como visíveis e invisíveis, forças e sentimentos, pessoas e bichos. Naquele momento, o papel historiográfico desse mito não me interessava, acima de tudo por conta da relativa escassez de trabalhos etnográficos publicados sobre os povos remanescentes de quilombos. Ao mesmo tempo, a ênfase de diversos pesquisadores em tentar comprovar os "credenciais" historiográficos dos relatos míticos dos povos de matriz africana nas Américas me incomodava, uma vez que, assim como outros autores (Gilroy, 1993; Scott, 1991), não acredito que cabe ao pesquisador euro-americano dizer se tais relatos são legitimamente historiográficos ou não.

Contudo, o processo de elaboração etnográfica da ecologia cosmopolítica dos Filhos deixou claro que as suas formas narrativas eram fundamentais para entender o princípio crucial de cuidado relacional, que também opera nas relações dos Filhos com o passado, uma vez que este ainda está ativo em sua paisagem. Quer dizer, se a Lenda das Cobras Crandes é legítima ou não enquanto fonte historiográfica parece ser, etnograficamente, menos importante do que pensar como os Filhos concebem e interagem com o passado, com o conhecimento sobre esse passado, e, assim, como esse mito e outras práticas narrativas podem impelir-nos a re-pensar acerca do que as palavras são capazes e, até, do que elas podem ser. Nesse sentido, penso no mito em questão como mecanismo de re-lembrar, diferente daquele introduzido acima na fala do Daniel, e talvez enquanto outra solução para o problema, levantado pelos Filhos de forma geral, do perigo de se falar sobre o passado: o perigo do conhecimento e, portanto, das palavras.

Interessante notar que essa é uma solução que as lideranças quilombolas, como Daniel, não costumam tomar. Daniel menciona a lenda em suas falas, outro coordenador da Arqmo chegou a colocá-la no papel a fim de ser impressa pela associação como arma na luta pela titulação. Porém, não foram eles os que contaram o mito para mim diversas vezes, em suas diferentes versões. Trata-se de um mecanismo de re-lembrar utilizado principalmente pelos mais velhos, velhos enrolados, como os Filhos diriam, na sua interação com crianças e pesquisadores: pessoas que estão aprendendo sobre a vida no Erepecuru. Assim, toda vez que eu chegava na casa de um Filho mais velho, a lenda era o relato que eles ofereciam, em um primeiro momento, sem qualquer solicitação da minha parte; ou, talvez, somente porque a minha figura de "pessoa de fora" e "doutora", como eles me chamam, suscitava essa narrativa. Portanto, podemos dizer que a necessidade de se contar um passado que não pode ser dito, porque ele adoece, para alguém que não o conhece requer pessoas com o dom de Daniel e mecanismos como a lenda. 
O mito é, assim, uma solução para o ato difícil, mas necessário, de re-lembrar, não somente nas interações com o Estado, mas também com todos os que estão chegando; solução que traz para perto de forma segura o que não pode ser dito por qualquer um, senão por aqueles que têm maior capacidade de controlar o conhecimento e, por isso, são "enrolados" - os velhos. Assim, advertem os que vão transitar naquela paisagem e a desconhecem de algo perigoso que ainda está presente (como o passado), dos piores tipos de conflitos (aqueles entre irmãos), de como essas brigas mudam o mundo e do trabalho poderoso do sacaca (o curador que mais enxerga entre os Filhos). O mito possibilita falar sobre a chegada dos seus antepassados de forma circunscrita, e sobre como esses antepassados - que eles chamam de negros escravos fugidos - foram, de certa forma, adotados pela paisagem e geraram outro tipo de gente, os Filhos do Erepecuru, os remanescentes: os que sobreviveram aquele tempo por um ficar tranquilo frágil, que precisa de manutenção, que depende de pessoas Coletivas que re-lembram de diferentes formas.

\section{RE-ESQUECER}

Como opera o perigo dos relatos sobre o passado? Recebi a seguinte resposta do Daniel: "imagina só escutar a maneira com que os seus parentes foram maltratados e ferrados, o sofrimento de ficar perdido numa mata dessas, é muita tristeza, é uma coisa que pode adoecer a pessoa" (minha ênfase). Seria, portanto, plausível dizer que, para os Filhos e outros povos de matriz africana nas Américas, o perigo desses relatos está localizado na possibilidade de reviver uma experiência traumática que lhes pertence enquanto descendentes de negros escravos fugidos. Seria, portanto, uma espécie de 'trauma cultural' (ver Eyerman, 2001; Alexander et al., 2004), diretamente conectado a comportamentos contemporâneos - como o 'isolamento consciente', sugerido por O'Dwyer-e subjacente a uma identidade coletiva. Do ponto de vista etnográfico, porém, tal interpretação traria pelo menos dois problemas. O primeiro é, mais uma vez, a 'narrativa de continuidades' contida em tal leitura sociológica, que é contrária à própria interpretação dos Filhos sobre a sua ancestralidade (ver, especialmente, Sauma, 2013), a qual opera pela marcação de uma relação de diferença ou uma 'relação que separa' (Strathern, 1988). E o segundo problema - que nos levará a uma consideração etnográfica de como o perigo das palavras opera entre os Filhos - é que a noção de 'trauma cultural' também parte do pressuposto de que a memória inicia com uma experiência emocional e intelectual.

Nessa visão, de influência freudiana, a doença seria a expressão de um evento traumático bloqueado pela 'supressão' ou 'repressão', que só seria aliviada por meio da reflexão verbal e catártica (Eyerman, 2001: 33; Smelser, 2004: 33); 
quer dizer, por meio da memória coletiva. Assim, a doença, que é causada pela repressão de uma memória coletiva, seguiria um processo de somatização, de inscrição corporal de um processo psíquico: interpretação plausível, porém alheia às concepções e práticas refinadas dos Filhos do Erepecuru em torno da doença, sobre a relação entre corpo e mente e, além disso, acerca das consequências da verbalização do passado. Como vimos acima, tais concepções e práticas operam por meio de mecanismos específicos de 're-lembrança' e, como veremos nesta seção, também envolvem técnicas para o 're-esquecimento', que não admitem a noção de 'repressão' nos termos freudianos. Aqui, a experiência da memória não implica, em primeiro lugar, um processo intelectual e emocional e, somente depois, uma afecção corporal. Em vez disso, o ato de re-lembrar sempre compreende coisas que têm a capacidade de penetrar a carne e passar para o corpo e para a mente da pessoa de uma vez só, afetando - pela cura ou doença - a sua mãe do corpo, ciência e juízo: elementos da pessoa que têm uma relação horizontal entre si.

Voltando ao início, à explicação de Daniel sobre por que é perigoso falar acerca do passado de fuga da escravidão, quero propor que, para entendermos essa afirmação - e, assim, as concepções e práticas dos Filhos relativas à memória, ao corpo, à mente e à pessoa -, é importante explicitar etnograficamente como "muita tristeza" é perigosa e como ela "pode adoecer a pessoa". Para isso, volto a nossa atenção a um dos princípios da ecologia cosmopolítica dos Filhos, a saber, a forma com que as interações ou relações entre os diferentes elementos ou, como os Filhos diriam, as diferentes coisas do cosmos-que incluem palavras, o passado, os sentimentos, as forças e os corpos -implicam a sua interpenetração ou a invasão de lugares e pessoas.

Esse princípio relacional constitui-se no meu trabalho (ver Sauma, 2013) por uma reflexão etnográfica em torno de outro relato sobre o passado, que descreve como a primeira localidade dos remanescentes abaixo das cachoeiras do rio Erepecuru, o Puraqué, foi contexto de uma briga entre parentes que resultou no seu abandono. A tristeza em locais abandonados, como o Puraqué, leva os Filhos a se distanciarem dos mesmos, nas suas idas e vindas no rio, mesmo quando são locais de ampla fartura para a pesca e a caça, pois são lugares fechados que têm uma coisa. O mesmo acontece com o relato sobre a briga no Puraqué: evita-se contá-lo por inteiro por conta da tristeza que este contém. Essa tristeza é perigosa porque pode deslocar a mãe do corpo da pessoa - órgão que reside no umbigo que regula o sangue e a nutrição do corpo e, portanto, o seu bem-estar e a sua tranquilidade -, como, por exemplo, no caso dos homens que são abandonados por suas esposas: eles guardam uma coisa dentro deles, entregam-se à bebida, tornando-se homens feios, com corpos a bertos a tudo o que passa. Assim, a tristeza ingressa nos corpos e nos lugares, abrindo-os e fechando-os, deixando espíritos malignos tomar conta, como no caso do Puraqué, gerando corpos e 
lugares sujos, cheios de besteira, doentes, ou seja, descuidados e sem possibilidade de ficar tranquilos.

Partindo das concepções dos Filhos, portanto, a tristeza (entre outras emoções) aparece como coisa e como força e sentimento, elemento que, ao se aproximar da pessoa (por qualquer meio), entra no seu corpo em um processo transformacional que a esgota, tornando-a vulnerável. Lembra, portanto, a análise de Holbraad $(2007,2014)$ acerca da relação interna entre poder e pó, ambos designados como aché no Ifá cubano. Como o autor explica, a única maneira de superar a "contradição" causal e conceitual que vemos na afirmação no Ifá de que o pó e o poder são a mesma coisa seria superando outra distinção ocidental: aquela entre os objetos concretos e os conceitos abstratos. Assim, segundo o autor, teríamos de entender o aché "nem como objeto nem como conceito mas como um pouco de cada: como objeto indiscreto e conceito que literalmente se transfere" (2014: 160). Acredito que a mesma análise pode ser feita, no Erepecuru, para pensar a relação entre o que os Filhos chamam de coisas e aquilo que eles chamam de força e sentimento, de maneira que também estaríamos diante de uma ontologia móvel (Idem), ponto ao qual retornarei. Como adendo, também diria que as palavras em si seriam, nesses contextos, um elemento exemplar do movimento, dessa relação de transferência ou de engajamentos que entram e, portanto, seriam exemplares da não contradição ou de uma participação de potências.

Nesse sentido, também é interessante levar em conta o argumento de Coldman (2011) em sua análise sobre a relação que atuais adeptos do Candomblé estabelecem com textos escritos sobre sua religião por pesquisadores no final do século XIx e início do século Xx. Refletindo sobre os limites representacionais da antropologia, segundo a crítica pós-moderna, e a importância de deixar de projetar "nossa vivência do campo intelectual" e, no seu lugar, "tentar aprender o que for possível acerca dessas outras formas de relação com a prática da leitura e do tratamento dos intelectuais", o autor propõe que:

poderíamos talvez dizer que tex tos como os de Nina Rodrigues (ou os próprios autores, quem sabe) apareceriam, aos ol hos daqueles acostumados com a possessão divina e com a transmissão do saber dos antigos, como espécies de meios por onde fluiria uma palavra e um conhecimento que não são os deles, "médiuns" ou "cavalos", que receberiam e transportariam algo que os ultrapassa muito, a palavra de Mãe Pulquéria, Martiniano do Bonfim ou Mãe Senhora-palavra que, como se sabe é em si mesma força e ação (Coldman, 2011: 424-425).

Importante notar aqui que é a palavra de outros que os textos transportam, palavras que movimentam palavras, palavras que são algo, força e ação. Assim, 
segundo o autor, seria relevante imaginar que no caso de:

um tex to em que Mãe Senhora está presente sendo lido por um adepto do candomblé, e não por um antropólogo (...) não creio ser absurdo imaginar que o que conta é muito mais a presença da força da grande sacerdotisa do que a mera apresentação de suas palavras. Afinal - e foi o próprio Bastide quem nos ensinou -, mesmo a mais tênue "participação" é incomensuravelmente mais potente do que a mais elaborada "representação".

Podemos afirmar que, nesses contextos, as palavras nunca serão "meramente apresentadas", pois elas carregam a força-sentimento das pessoas que as enunciaram originalmente, o que nos leva de volta à contemplação das dinâmicas de re-esquecimento dos Filhos do Erepecuru. A tristeza seria uma força-sentimento e uma coisa que é gerada pelo conflito, pelo abandono, pela morte, enfim, pela vida, que se transfere para dentro da carne, para dentro dos corpos e, por isso, muitos dos esforços dos Filhos estão direcionados à geração de alegria, força-sentimento que combate a tristeza e torna os corpos e os lugares animados e protegidos contra tudo o que traz o mal. Para manter a alegria, os Filhos também evitam falar e até pensar nos relatos tanto sobre o passado distante quanto sobre o passado recente, nos momentos em que a vida encontra a triste$z a$, pois enunciar esses eventos traz a tristeza para dentro do corpo daqueles que falam e escutam: as palavras são especialmente eficazes nessa transferência, assim como o pó é especialmente eficaz para a movimentação do aché no Ifá cubano. ${ }^{8}$ Dessa forma, re-lembrar um relato triste, tal como a briga que ocorreu no Puraqué ou a fuga dos antepassados das plantações e como ficaram perdidos na mata, é perigoso porque possibilita uma situação na qual o corpo da pessoa e a força-sentimento da tristeza encontram-se no mesmo lugar por meio da palavra daquele que lembra ou conta o relato, possibilitando a transferência entre diferentes coisas: : palavra, força e carne.

O perigo envolvido nas palavras implica em diversos mecanismos de moderação relacional com essas coisas, como parte de uma "pragmática do perigo" em que, assim como Suzane Vieira (2015: 148, minha ênfase) observa entre os quilombolas do al to sertão baiano, "[a]s palavras são administradas tendo em vista uma arte das consequências". Dois desses mecanismos nos interessam aqui-o segredo e o re-esquecimento-, considerando que, entre os Filhos, esses dois mecanismos conversam entre si, por vezes até se sobrepondo. Levanto neste ponto a questão do segredo, pois acredito que os Filhos mantêm um corpus de palavras secretas - as rezas, palavras feitas para curar corpos abertos e fechados-que nos ajuda a compreender ainda mais a carnalidade e força das palavras.

Maria de Souza, mãe do Daniel e consertadora, conserta corpos com rezas e
8 Importante dizer que isso também procede para a geração de alegria entre os Filhos, tanto que a brincadeira que produz a alegria nas suas festas e nos movimentos tem de envolver a elaboração de piadas e versos

8 Infelizmente, não tenho espaço para dar a devida atenção a esse conceito aqui, mas vale enfatizar que o conceito nativo de coisa parece fazer o trabalho de simetrização ou horizontalização entre esses diferentes elementos nas falas dos Filhos. Essa é uma questão à qual pretendo voltar futuramente. 
remédios caseiros, havendo se especializado no conserto de rasgaduras. Ela tem o corpo fechado. Isso significa que nada ruim entra nela, sua ciência e seu juízo são firmes, e que ela tem um anjo da guarda. Maria mora na cidade de Oriximiná desde que seu falecido marido, o poderoso sacaca Chico Melo, adoeceu, por conta de um feitiço, no início da década de 1990. Antes disso, ela tinha passado vinte anos sem descer para a cidade, morando na comunidade do Jauari no rio Erepecuru. Ela era animadora da comunidade, conhecedora de muitas músicas, muitas adivinhações, muitas histórias e muitas piadas. E continua sendo assim na cidade onde, segundo os seus filhos, ela montou um mocambo no seu quintal. É uma consertadora conhecida por todos, recebendo todo tipo de gente na sua casa, gente pequena e graúda. Até prefeitos já consertaram rasgaduras com ela e, por isso, ela tem muitos amigos e recebe muitos presentes. A reza de Maria para consertar rasgaduras, segundo os seus parentes, é muito poderosa. Ela diz que recebeu essa reza e outras rezas - que são todas secretas, nunca enunciadas em voz alta - do seu tio, que também era consertador e que percebeu, desde cedo, que Maria tinha esse dom, e que ela poderia usar essa reza para fazer o bem. É somente uma das suas rezas, mas a que ela mais usa. Todos os dias ela recebe pelo menos duas visitas, às vezes até dez, que buscam consertar uma rasgadura. As pessoas chegam a pé baixo o sol quente, de manhã, à tarde ou mesmo no meio do dia. Chegam de moto e até de carro grande. E Maria recebe a todos com seu sorriso e piadas, na sua casinha na praça Centenário. Alguns pagam com farinha, outros com dinheiro e até com móveis.

As rasgaduras são lesões da carne que normalmente ocorrem quando a pessoa está fazendo algum esforço muito grande: o bebê com muita raiva, o jogador de futebol, a mulher enquanto lava ou carrega a roupa etc. A carne rasga e a consertadora (ou consertador) usa a sua reza para costurá-la. Maria conserta da seguinte forma: primeiro ela usa outra reza para benzer a pessoa que busca a sua ajuda, sussurando-a enquanto faz o sinal da cruz em determinados pontos do corpo: dos dois lados da testa, sobre o coração, o umbigo, os tornozelos e os punhos. Esse primeiro benzimento ajuda ela a fazer o seu diagnóstico, pois às vezes a pessoa chega achando que tem rasgadura em determinado lugar quando na verdade é uma desmentidura (um deslocamento dos ossos) que causou uma rasgadura em outro lugar. A reza permite à Maria ver a carne da pessoa, sentir onde está doendo e o porquê, são palavras que funcionam como um tipo de Raios $x$, apontando a eficácia dessas palavras em mediar engajamentos ou relações que entram no corpo. Quando Maria encontra a rasgadura, ela se prepara para costurá-la. Dentro de uma lata, ela busca um quadrado de pano, uma agulha e uma linha. Enquanto sussurra a reza que costura a carne, ela costura o pano com alguns pontos retos pairando sobre o local da rasgadura. A costura do pano, segundo Maria, reforça as palavras, ajuda-as a penetrar na carne com mais força 
- mas o pano não é necessário, pois, como ela explica, essa reza é forte, ela pega na carne mesmo sem o pano. Após costurar a carne, Maria ainda cobre o local com um emplasto, algo que vai ajudar a carne a sarar. As fol has de sabiá são especialmente eficazes, mas o Salompas que se compra na farmácia também funciona.

Vemos então, nessa descrição, como as rezas, fórmulas compostas por palavras secretas, penetram o corpo: certas rezas ajudam a consertadora ou até o sacaca a ver e sentir o que está no corpo e na mente dos seus pacientes, outras costuram a carne, outras, ainda, abrem certos corpos, fazendo-os atacarem outros corpos com armas específicas -existem rezas para que o corpo do outro faça mil e uma coisas, e rezas que fecham os corpos para que nenhuma palavra, faca ou bala penetrem-nos. Assim, podemos entender porque são rezas secretas, transmitidas com cuidado - normalmente somente entre aqueles que têm o dom para usá-las de forma adequada -e sussurradas quando utilizadas: além de não poderem ser aprendidas por qualquer um, as rezas têm um efeito sobre todo corpo, seja o do paciente, o daquele que usa a reza ou o de alguém (um parente ou uma antropóloga) que esteja observando o conserto por algum motivo. Portanto, a reza precisa ser orientada para um local específico, bem como sua eficácia orientada por certos instrumentos (um pano que se costura também, por exemplo).

Voltamos a reconsiderar a força da tristeza contida no relato do Daniel. Seria possível dizer que, além de gerar a tristeza em um lugar, ao serem enunciados, os relatos tristes entram no corpo das pessoas que escutam o relato. Assim, mesmo as pessoas que não têm corpos abertos podem vir a ser adoecidas por esses relatos, de maneira que é preciso enunciá-los com cuidado para não adoecer: Daniel é o Filho que mais se dedicou à coleção dessas forças-palavras, a fim de utilizá-las nas reuniões do movimento quilombola. É com essas forças-palavras que Daniel, que tem o dom para tanto (assim como sua Mãe tem o dom de consertar), contribui há muitos anos para o ficar tranquilo dos Filhos, trazendo benefícios aos seus parentes, que não têm o dom para fazer esse trabalho.

Para uma melhor compreensão dessas concepções e práticas, em conexão com a forma em que os Filhos se relacionam com a verbalização ou as narrativas sobre o passado, atenta-se às dinâmicas que o re-lembrar implica e, assim, à sua interdependência com o esquecimento, ou melhor, com o re-esquecer. Dois problemas interconectados surgem: um de ordem etnográfica e outro de ordem lógica; problemas que me levaram a introduzir esses dois conceitos próprios, 're-lembrar' e 're-esquecer', neste trabalho.

Primeiro, em relação ao problema etnográfico, senti a necessidade de introduzir conceitos para relacionar os atos de lembrar e de esquecer entre os Filhos, pois eles mesmos não nomeiam esses atos. Em vez disso, quando as lideranças quilombolas incentivam os seus parentes a falar sobre o passado de escravidão na luta pela titulação de suas terras, discorrem sobre a necessidade de resgatar o 
passado - termo amplamente difundido pelo Movimento Negro para falar sobre a necessidade de colocar a $(\mathrm{H})$ istória e a $(\mathrm{C})$ ultura dos povos de matriz africana no Brasil em primeiro plano. Ao mesmo tempo, quando os Filhos conversam, entre si, sobre a dificuldade de convencer os seus parentes a participar do movimento e falar sobre o passado, ou mesmo sobre a própria dificuldade de se sentir mobilizados por essa luta, utilizam expressões como eu sei que não levam a sério ou eu não acreditava. Assim, em termos etnográficos, acredito que, por trás dos conceitos re-lembrar e re-esquecer, podemos identificar duas dinâmicas: 0 resgate - entendido como um ato de abertura do conhecimento - e o abandono ou fechamento de narrativas sobre o passado, este último efetuado pela brincadeira e pelo não acreditar.

O segundo problema, dessa vez de ordem lógica, que me levou a introduzir aqui esses dois conceitos remete à dificuldade inerente de se falar sobre o esquecimento na antropologia contemporânea. Acredito que, de certa forma, essa dificuldade está relacionada à impossibilidade de se pensar uma "ars oblivionalis" ou técnica do esquecimento a partir da semiótica ocidental, conforme argumentado por Umberto Eco (1988), uma vez que essa semiótica foi formulada com base em uma "arte da memória". Ou seja, a semiótica é uma técnica de tornar presente e não de tornar ausente (Eco, 1988: 258). Sendo assim, permite, no máximo, lembrar-se de que se quer esquecer algo e não, propriamente, esquecer. Segundo o autor, a única forma de "produzir o esquecimento" seria pelo excesso e não pela deficiência, quer dizer, por meio da sobreposição retórica.

Os parentes de Daniel, aqueles que escutam seus enunciados potentes e tristes nos movimentos, nas brincadeiras, nos momentos de confraternização, reconhecem que ele faz isso para o bem de todos, por mais que possam se irritar com a repetição das histórias e por mais que não gostem de escutá-las. Com isso, para orientar o efeito dessas forças-palavras, os Filhos utilizam um método de moderação, que leva as palavras em direção ao ato de re-esquecer pela maioria, que é a risada. Normalmente, logo após os momentos mais públicos dessas confraternizações, em que os parentes do Daniel também se preocupam em tratar a sua fala com seriedade e confirmá-la, ou até mesmo durante as suas falas, outros começam a encontrar modos de tirar a tristeza dessas palavras, repetindo-as de forma quebrada, entrecortada por risos, remendando o seu tom. As forças-palavras que trazem a tristeza que adoece, mas que precisa ser re-lembrada nos encontros dos Filhos com o Estado, podem ser, portanto, dissolvidas e, assim, re-esquecidas. Moderar é, entre muitas coisas, colocar forças-palavras em movimento, enunciando-as e transformando-as em outras forças e, assim, a tristeza é transformada em alegria.

Daniel sabe que os seus parentes fazem isso e fala: "eu sei que as pessoas riem de mim, eu sei que se irritam comigo, mas é isso que eu sei fazer, que faço 
há muito tempo". Ao mesmo tempo, porém, ele faz algo muito parecido com os relatos míticos dos velhos, como a Lenda das Cobras Crandes: Daniel e outros coordenadores das associações quilombolas da região têm o hábito de falar sobre os relatos míticos sem replicá-los, como mostrei anteriormente. Nessas falas, os coordenadores contam que os relatos fazem parte do costume dos velhos, aqueles que têm a capacidade de ser enrolados, de ser perigosos. E, em muitas dessas conversas, uma das técnicas mais comuns de dissolução do poder das forças-palavras ocorre com o questionamento sobre as partes dos relatos que aconteceram e as que não aconteceram. Como disse Augusto, coordenador da comunidade da Pancada, certa vez, durante uma conversa entre vários coordenadores: "esses velhos são muito enrolados, eles falam coisas pra tentar fazer a gente agir de certo jeito, a lenda das cobras, por exemplo, têm coisas ali em que eu não acredito".

Conforme descrito em outro lugar (Sauma, 2013), entre os Filhos, acreditar implica ter fé em algo, como a fé em Deus ou no sacaca, o que significa usar aquilo no qual se tem fé. Por exemplo, os acidentes nos barcos ou na roça podem ocorrer quando as pessoas envolvidas não têm fé em Deus e, assim, não usam a inteligência que Deus Ihes conferiu. Acreditar, portanto, não seria o oposto de desacreditar, de duvidar da existência de Deus, mas sim de não utilizar, de não colocar em prática.

Podemos dizer que, assim como nos relatos tristes de Daniel, que são re-esquecidos pela risada, os mitos que solucionam o re-lembrar dos mais velhos também podem ser dissolvidos, moderados, colocados em movimento com a frase "eu não acredito". Vale lembrar que, como trata de forças-palavras, a Lenda das Cobras Grandes também é perigosa, trazendo à superfície a permanência das cobras grandes na paisagem e, assim, advertindo as crianças (e os antropólogos) sobre o perigo das brigas entre irmãos - que causam transformações cosmogônicas - e sobre o fato de que o ficar tranquilo dos Filhos é um estado frágil, que precisa de manutenção. Esses são os relatos que causam o medo diário do movimento ao longo do rio, o distanciamento que os Filhos mais novos sempre buscam dessas narrativas, mesmo quando também as utilizam em determinados momentos. São relatos que precisam de cuidados constantes, que desfazem as forças-palavras que transgridem o corpo e refazem-nas nos momentos certos, em um constante movimento entre o re-lembrar e o re-esquecer.

\section{POR UMA ONTOLOGIA MÓVEL}

A mobilidade suscita, como forma de apontar conexões a serem aprofundadas futuramente, a possibilidade de que entre os Filhos e outros povos de matriz africana, ou melhor, outros povos em movimento-acerca da relação entre coisas, 
e entre coisas e pessoas -, opere aquilo que Holbraad (2014) denomina como uma 'ontologia móvel' para falar sobre o problema-prático da divinação no Ifá cubano, em que:

são potenciais as relações entre as divindades e os humanos que a divinação deveria estabelecer, e é somente esse potencial - o potencial do movimento direcionado - que o pó de aché garante, como solução para o verdadeiro problema das travessias que os deuses precisam sofrer para serem presentificados e ativados na divinação (Holbraad, 2014: 163, minha tradução).

A discussão de Holbraad gira em torno da relação entre as divindades e os humanos que, segundo o autor, é mediada pelo aché, força que é coisa (pó) e conceito, sendo a mobilidade também qualidade inerente ao pó (à coisa), pois consiste em uma 'coleção de partículas' que tem a capacidade 'intensiva' de ser mobilizada (Holbraad, 2014: 162). Holbraad argumenta que a noção de 'ontologia móvel' seria uma forma de repensar o uso da oposição judaico-cristã entre transcendência e imanência na análise de cosmologias e práticas religiosas como o Ifá cubano. Segundo o autor, a necessidade de buscar outros conceitos para descrever a qualidade simultânea de majestade, distância cosmológica e presença ritual das divindades, que tal oposição permite descrever, é dada pelo fato de que a ruptura ontológica, que também a fundamenta, não procede no Ifá. Assim, com base nas potencialidades que parecem descrever a relação entre humanos e deuses no Ifá, Holbraad (2014: 172) elabora o argumento de que tal relação depende de transformações "ao longo de um eixo intensivo e autodiferenciador que corre entre a distância ontológica relativa da transcendência e a proximidade relativa da imanência". Ou seja, segundo o autor, e pelo que entendo do seu argumento, essa relação depende do potencial divino de transformação ontológica ao longo do eixo ser Deus - ser aché - ser pó.

Esse argumento é interessante para o presente trabalho, pois, como vimos acima, é possível dizer que, no Erepecuru, a transformação e, com isso, a mobilidade, é inerente às palavras que também são coisas, forças e sentimentos, ocorrendo simultaneamente de forma intensiva e extensiva. Quer dizer, nesse contexto, a mobilidade das palavras ocorre tanto em termos da transformação intensiva de intento entre os polos do eixo reesquecer-relembrar-palavras sérias são colocadas em movimento ao serem transformadas em piadas e, assim, a força e o sentimento que elas carregam também são transformados-, quanto em termos de seu percurso extensivo em determinado espaço ao serem enunciadas, como as palavras das rezas que pegam na carne ou os relatos tristes que adoecem. Assim, é possível sugerir que as palavras, as quais inerentemente causam transformações corporais, também podem sofrer transformações inten- 
sivas, ou ontológicas. Crucial para essa sugestão é entender que as palavras são mais do que palavras, no sentido de serem mais que simplesmente signos que representam ou apresentam coisas, forças e sentimentos. Ou seja, não é tão estranho fazer a relação analítica entre a transformação ontológica das divindades no Ifá cubano e as transformações intensivas das palavras entre os Filhos, pois no Erepecuru as palavras - assim como as divindades, no Ifá - também podem ser força e coisa.

Ao mesmo tempo, a análise de Holbraad é claramente constituída a partir de uma reflexão acerca da transcendência das divindades: a mobilidade ontológica é colocada em jogo pelo autor por conta da distância ontológica entre divindades e humanos, o que faz sentido para descrever a forma em que os Filhos falam sobre a sua relação com Deus e os santos católicos (ver Sauma, 2013), mas não é o caso da relação entre pessoas e palavras. Muito pelo contrário, no Erepecuru, as pessoas, as palavras, as coisas, as forças, os espíritos, os bichos, todos parecem conviver em um espaço mais ou menos contínuo; todos habitam um plano - o rio Erepecuru, que é feito de terra e várzea, floresta e pontos fundos da mata e dos rios - que opera a partir da imanência (Deleuze e Guattari, 1997). Assim, talvez seria o caso de prescindir da noção de 'mobilidade' para descrever a relação entre esses elementos em favor de noções como 'descontinuidades internas' (Strathern, 2005), 'diferenciação intensiva' (Viveiros de Castro, 2006) ou 'devir' (Deleuze e Guattari, 1997), segundo as quais tais elementos poderiam habitar:

um regime ontológico comandado por uma diferença intensiva fluente absoluta, que incide sobre cada ponto de um contínuo heterogêneo, onde a transformação é anterior à forma, a relação é superior aos termos e o intervalo é interior ao ser (Viveiros de Castro, 2006: 324 apud Holbraad, 2014:164).

Sem dúvida, tais noções dão conta de diversas dimensões nas descrições dos Filhos do Erepecuru acerca da relação entre palavras, forças e coisas. Ao mesmo tempo, também acredito que-como foi desenvolvido a partir de outros campos etnográficos e metafísicos - tais conceitos devem ser tomados como pontos de partida para a descrição da qualidade singular de movimento de transformações/relações/intervalos que estão em jogo nessas descrições.

O conceito de movimento comunica, portanto, certa qualidade relacional, que já foi apresentada na etnografia acima e à qual voltamos agora para refletir sobre o lugar da noção de ontologia móvel no presente trabalho, mesmo que de forma bastante diferente à que Holbraad usa a fim de desenvolver essa noção. $\mathrm{Na}$ descrição antecedente sobre como a tristeza pode adoecer as pessoas, sugeri que as interações ou relações entre os diferentes elementos do cosmos implicam 
conexões que podem "entrar" nos lugares e nas pessoas. Nesse processo, e nos atendo à relação entre palavras enunciadas em relatos sobre o passado e corpos, as palavras adoecem a pessoa ao entrar no seu corpo e deslocar a sua mãe do corpo, o que deixa o corpo aberto. Esse efeito é mais incomum para quem tem o corpo fechado-quer dizer, quem tem mais juízo e ciência de si-, e mais frequente para quem já tem o corpo meio aberto. Dessa forma, na descrição dos Filhos sobre a transformação corporal que ocorre como efeito da relação entre corpos e palavras, podemos identificar três tipos de movimento: primeiro, o movimento das palavras entre o corpo do enunciador e o corpo de quem escuta o seu relato, que tem ou não tem juízo para deixar tudo o que passa entrar em seu corpo; segundo, o movimento de penetração das palavras no corpo através da mente ou da carne; e, terceiro, a abertura do corpo, seja este anteriormente fechado ou meio aberto, resultando em diferentes graus de abertura.

Ao mesmo tempo, as elaborações dos Filhos sobre como as palavras podem entrar na pessoa e transformar o seu corpo trazem à tona uma questão interessante em torno da oposição ser-não ser. Operante nas descrições sobre pessoas com corpos fechados e com corpos meio abertos está a observação de que é possível ter o corpo totalmente aberto, como, por exemplo, no caso das crianças pequenas que, por isso, não têm ciência de ser gente. Assim, os Filhos do Erepecuru explicam que o corpo da criança é muito facilmente tomado por diferentes forças e sentimentos, levando-a potencialmente à morte em poucos passos. Esse é o caso das crianças que sofrem com o quebranto, por exemplo, que normalmente é causado quando o cansaço de alguém recém-chegado de uma longa viagem domina o corpo da criança por haver recebido muitos agrados do viajante por meio de suas palavras, seu toque e seu olhar; doença que também pode ser curada por uma reza específica.

É importante enfocar, brevemente, o uso da noção de ciência para descrever o estado ontológico de ser gente no caso das crianças pequenas, pois também é utilizada pelos Filhos para descrever a sua relação com os invisíveis, ou espíritos, que igualmente habitam as águas e as florestas do Erepecuru. Conforme descrito em outro lugar (Sauma, 2013), os invisíveis do Erepecuru são perigosos justamente porque não têm ciência de que não são gente, pois não têm corpos, mas continuam se comportando como se tivessem: jogando futebol, morando em casas no fundo do rio e desejando relações com os donos visíveis do Erepecuru, quer dizer, com os Filhos. É possível fazer a conexão, portanto, entre a falta de ciência dos invisíveis e a das crianças pequenas: de um lado, os invisíveis, que não têm ciência de não ser gente e, de outro, as crianças, que não têm ciência de ser gente. $O$ pivô dessa conexão é o corpo: de um lado, os invisíveis, que não têm corpos e, de outro, crianças pequenas com corpos abertos; de um lado, os invisíveis, que também são coisas-forças-sentimentos que podem entrar nos corpos e, de outro, as 
crianças, que são facilmente dominadas por coisas-forças-sentimentos.

O que estou sugerindo é que, nessas elaborações, a ciência é um instrumento de mensuração ontológica crucial, que opera em torno da relativa abertura e fechamento do corpo e, com isso, entre ser gente e ser coisa-força-sentimento, ou seja, não ser gente. Entre ter o corpo aberto e ter o corpo fechado, portanto, identificamos a diferença entre ser gente e não sergente: dualidade que é complexificada pelo fato de que é possível ter um corpo meio aberto ou que não fechou completamente no processo de crescimento e amadurecimento desde a infância, o qual pode ser fechado por rezas. Assim, e parafraseando Holbraad sobre a noção de ontologia móvel, é possível dizer que entre não ser e ser gente, respectivamente, corre um eixo intensivo e autodiferenciador entre a distância ontológica relativa da abertura corporal até a proximidade relativa do fechamento corporal: estados que podem ser desencadeados por palavras que abrem e fecham corpos.

Insisto na noção de 'distância' ontológica, mesmo ao tratar de um plano que opera a partir da imanência e do devir, pois, entre a visibilidade das pessoas com corpos fechados e a invisibilidade das forças-coisas-sentimentos, as análises dos Filhos também enfatizam movimentos e lugares. Quer dizer, suas elaborações acerca do ser e do não ser contêm uma cartografia corporal, como já vimos, e, ao mesmo tempo, uma cartografia espacial refinada, em que as pessoas (que são gente) habitam e transitam por lugares abertos e limpos e as coisas-forças-sentimentos (que não são gente) habitam e transitam por lugares fechados e fundos. Assim, entre a distância ontológica relativa de abertura corporal e a proximidade relativa do fechamento corporal também corre um eixo intensivo e autodiferenciador entre a relativa abertura/fechamento dos corpos e a relativa abertura/ fechamento dos lugares. A noção de ontologia móvel sobre a qual pondero aqui - e que também coloco em movimento com o intuito de apontar as potencialidades, em todos os sentidos da palavra, da etnografia apresentada-pretende marcar a profunda distância entre os lugares abertos e os lugares fechados que também efetiva a oposição ser e não ser gente, respectivamente, entre os Filhos do Erepecuru.

Assim, a noção de 'ontologia móvel' pode ser explorada nesse contexto, traçando uma conexão interessante entre a ecologia cosmopolítica dos Filhos e a forma em que outros povos de matriz africana nas Américas definem e agem em relação aos diferentes elementos e níveis ontológicos que compõem os seus mundos, considerando que a existência de diferentes níveis não necessariamente significa a ruptura entre os mesmos. Acredito que essa conexão também poderia ser estendida, de forma comparativa, é claro, a etnografias sobre outros povos em movimento, como forma de permitir o desdobramento etnográfico da análise sobre a 'potencialidade' da mobilidade, assim como enquanto meio 
de explicitar os conceitos nativos que nos permitiriam prescindir da oposição transcendência-imanência totalmente. Em relação à palavra, especificamente, e segundo análises oferecidas em trabalhos recentes (Ramo y Affonso, no prelo; Macedo e Sztutman, 2014; Sztutman, no prelo; Vanzolini, 2014), acredito que a comparação entre etnografias americanistas sobre os povos de matriz africana e sobre os povos guarani - para quem a alma é palavra que ergue a pessoa (Ramo y Affonso, no prelo) -é de especial interesse, apontando desdobramentos futuros para a presente reflexão, especialmente em torno da aparente diferença entre mundos em que a humanidade e mundos em que as coisas medeiam quase todas as relações.

Como forma de concluir, e voltando à relação entre movimento e esquecimento, em uma seção do seu lindo livro sobre a história dos mitos piro da Amazônia peruana, Peter Cow (2001: 96) apresenta uma análise da categoria mítica 'histórias esquecidas dos antigos', a qual ele sugere também fazer parte do processo mitopoético piro, em que novos mitos são gerados por meio da transformação radical de outros mitos. Cow propõe que essa categoria deve ser entendida como incluindo mitos que nunca foram enunciados ou escutados, ou pelo menos que não o tenham sido há muito tempo, mas que fazem certo sentido lógico para os Piro. Por mais que o esquecimento apareça de forma bastante diferente entre os Filhos, a indagação de Cow acerca do que o esquecimento significa para os Piro, e a forma em que opera dentro de sua mitopoeses, traz elementos interessantes para a atual reflexão. Naquele contexto, o esquecimento também aparece como marcador de um potencial infinito, daquilo 'que poderia ser' como forma de pensar o conhecimento de outrem e, portanto, como forma de colocar o conhecimento e os conceitos em movimento.

Entre os Filhos, a noção lévi-straussiana de que a geração mítica ocorre a partir da transformação também nos permite pensar no movimento de suas narrativas, em contraste com a (História) estática, legitimada, que o Estado demanda dos povos indígenas e tradicionais. Interessante, portanto, é a relação entre transformação e movimento a fim de pensar os mecanismos que os Filhos utilizam para, em primeiro lugar, presentificar o conhecimento e, com isso, as palavras presentes - quer dizer, tornar essas coisas-forças-sentimentos presentes-e, em um segundo momento, para desfazer as palavras, esvaziá-las de potência, sem desqualificá-las, uma vez que elas podem precisar reaparecer em outro momento. Assim, como sugerido acima, re-lembrar e re-esquecer são atos que colocam palavras em movimento intensivo, atos que abrem e fecham o conhecimento, respectivamente, ao mesmo tempo em que a mobilidade extensiva - entre e através de corpos e lugares abertos e fechados - também seria uma qualidade inerente às mesmas.

Em sua reflexão sobre os Piro, Cow (2001: 98) também propõe que o proble- 
ma do mito esquecido traz à tona um problema metodológico importante, pois, segundo o autor, "estamos cegos aos processos de mitopoeses enquanto estes estão criando mitos totalmente novos (...) nunca teremos certeza de que a sua ausência das coleções míticas anteriores não decorreu de mero descuido". No presente trabalho, o esquecimento também envolve um problema metodológico fundamental, dessa vez de caráter político, relativo à análise antropológica de outros regimes de conhecimento, mas que também envolve certa 'cegueira'. Pois se, para os antropólogos ocidentais, o problema do esquecimento levanta questões de ordem causal ou conceitual, quer dizer, de ordem lógica, fica evidente na etnografia apresentada acima que para os Filhos, e provavelmente para outros povos (e portanto outros antropólogos), as questões são de outra ordem. A forma em que pensamos a palavra está no centro dessa questão, dessa cegueira, e, com isso, uma ontologia móvel em que coisas-palavras se relacionam pelo movimento e por relações que adentram e possuem corpos que abrem e fecham, nos leva a enxergar outros mundos possíveis. A questão metodológica que está em jogo aqui é, assim, a nossa capacidade de enxergar e, para tanto, a habilidade de permitir que outros mundos transformem até aquilo que a gente acredita ou pretende dominar acima de tudo - a palavra e o conhecimento-aceitando que estes não pertencem, somente, à ordem da lógica e da memória, e que não podem ser dominados e congelados, pois estão sempre em carne viva.

Julia F. Sauma possui graduação em Antropologia pelo Coldsmiths' College, University of London (2001); mestrado em Antropologia Social pelo PPGAS do Museu Nacional/UfRJ (2007); mestrado em Pesquisa Antropológica (2008) e Doutorado em Antropologia (2014), pela University College London. É pós-doutoranda no PPCAS da FFLCH/USP e bolsista do PNPD (Programa Nacional de Pós-Doutorado) da Capes.

\section{REFERÊNCIAS BIBLIOGRÁFICAS}

ALEXANDER, Jeffrey et al.

2004 Cultural Trauma and Collective Identity. Los

Angeles, University of California Press.

CAMPOS, Augusto; CAMPOS, Haroldo; e PIGNATARI, Décio

1956 "Manifesto Concretista". ad, arquitetura e decoração, n. 20. 
Dossı̂́ | Julia F. Sauma | Palavras carnais: sobre re-lembrar e

DELEUZE, Gilles e GUATTARI, Félix

1997 [1980] Mil platôs: capitalismo e esquizofrenia. São Paulo, Editora 34.

ECO, Umberto e MICIEL, Marilyn

1988 "An Ars Oblivionalis? Forget It!". PMLA, vol. 103, n. 3: 254-261.

EYERMAN, Ron

2001 Cultural Trauma: Slavery and the Formation of A frican American

Identity. Cambridge, Cambridge University Press.

GILROY, Paul

1993 The Black Atlantic: Modernity and Double Consciousness.

Cambridge, MA, University of Harvard Press.

GOLDMAN, Marcio

2011 "Cavalo dos Deuses: Roger Bastide e as transformações das religiões de matriz africana no Brasil". Revista de Antropologia, vol. 54, n. 1: 407-432.

GOW, Peter

2001 An Amazonian Myth and its History. Oxford, Oxford University Press.

HOLBRAAD, Martin

2014 "Truth Beyond Doubt: Ifá Oracles in Havana". HAU, Journal of Ethnographic Theory, vol. 2, n. 1: 81-109.

2012 Truth in Motion The Recursive Anthropology of Cuban Divination. Chicago e Londres, University of Chicago Press.

LIMA, Joaquim

1992 História dos negros que através da luta conseguiram libertar-se dos senhores de escravos. Pará, 12 dat.

MACEDO, Valéria e SZTUTMAN, Renato

2014 "A parte de que se é parte. Notas sobre individuação e divinização (a partir dos Guarani)". Cadernos de Campo, n. 23: 287-302.

O'DWYER, Eliane

2002 "Os Quilombos do Trombetas e do Erepecuru-Cuminá". In (org.). Quilombos: identidade étnica e territorialidade.

Rio de Janeiro, Editora FGV, pp. 255-280. 
OVERING, Joanna

1989 "Styles of manhood: an Amazonian contrast in tranquility and violence". In HOWELL, S. e WILLIS, R. (orgs.), Societies at Peace. Londres, Tavistock Publications, pp 79-99.

RAMO Y AFFONSO, Ana

No prelo "O que nos levanta sobre a terra: alegria e saudade fazendo parentesco". In GALLOIS, Dominique e MACEDO, Valéria (orgs.), Nas redes guarani. Um encontro de saberes, traduções e transformações.

SAUMA, Julia

2013 The Deep and the Erepecuru: Tracing Transgressions in an Amazonian Quilombola Territory. Londres, tese, University College London.

2014 "Entrosar-se, uma reflexão etnográfica afroindígena". Cadernos de Campo, n. 23: 257-270.

2015 "Consenso unânime: movimentos pela tranquilidade e a sobreposição de pensamentos entre os Coletivos-Quilombolas de Oriximiná". In GRUPIONI, D. F. e DE ANDRADE, L. M. M. (orgs.), Entreáguas bravas e mansas: índios e quilombolas em Oriximiná. São Paulo, Comissão Pró-Índio e lepé, pp. 234-251.

SCOTT, David

1991 "The Event, This Memory: Notes on the Anthropology of African Diasporas in the New World". Diaspora: A Journal of Transnational Studies, v. 1: 261-284.

SMELSER, Neil

2004 "Psychological Trauma and Cultural Trauma". In ALEXANDER et al. (orgs.) Cultural Trauma and Collective Identity. Los Angeles, University of California Press.

SZTUTMAN, Renato

No prelo "O desabrochar da palavra: sobre o encontros dos Clastres com os Guarani". In GALLOIS, Dominique e MACEDO, Valéria (orgs), Nas redes guarani. Um encontro de saberes, traduções e transformações.

VANZOLINI, Marina

2014 "Daquilo que não se sabe bem o que é: a indeterminação como poder nos mundos afroindígenas". Cadernos de Campo, n. 23: 271-285. 
VIEIRA, Suzane

2015 Resistência e pirraça na mal hada: cosmopolíticas quilombolas no Alto Sertão de Caetité. Rio de Janeiro, tese, UFRJ.

VIVEIROS DE CASTRO, Eduardo

2006 "A floresta de cristal: notas sobre a ontologia dos espíritos amazônicos". Cadernos de Campo, n. 14/15: 319-338.

VIVEIROS DE CASTRO, Eduardo; PEDERSEN, Morten; e HOLBRAAD, Martin 2014 "The Politics of Ontology: Anthropological Positions". FieldsightsTheorizing the Contemporary, Cultural Anthropology Online.

\section{Carnal Words: About Re-Remembering and Re-Forgetting, Being and Not Being, among the Sons of Erepecuru}

\section{ABSTRACT}

In this work, I explore the analytical potential of what Martin Holbraad calls 'ontographic method', based on the reflections of the Sons of Erepecuru about the process of remembering and forgetting reports about their ancestors, and the performance of these words on the body. The first step is a consideration of the importance that the Sons confer to the forgetfulness of their reports about the arrival of the ancients to the river Erepecuru, in the city of Oriximiná, state of Pará. From this ethnographic question, I describe how the need to forget and the care inherent to the act of remembering are related to the power of words to mobilize forces and feelings, healings and diseases, into the person. Such ethnographic reflection makes it possible to suggest how language and experience are related by the Sons of the Erepecuru, and how this relationship operates on the basis of a mobile ontology.

Recebido em setembro de 2016. Aceito em setembro de 2016.

\section{KEYWORDS}

Remnants of Quilombos, Ontology, Forgetfulness, Words, Body. 